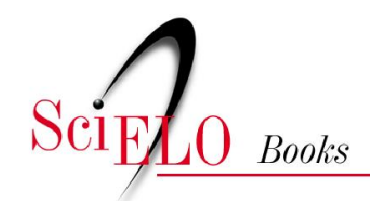

\title{
Aplicação de técnicas de produção mais limpa no desmonte de rocha e sua contribuição para a saúde do trabalhador
}

\author{
Julio Cesar de Pontes \\ Waleska Silveira Lira \\ Vera Lúcia Antunes de Lima
}

\section{SciELO Books / SciELO Livros / SciELO Libros}

PONTES, JC., LIRA, WS., and LIMA, VLA. Aplicação de técnicas de produção mais limpa no desmonte de rocha e sua contribuição para a saúde do trabalhador. In: LIRA, WS., and CÂNDIDO, GA., orgs. Gestão sustentável dos recursos naturais: uma abordagem participativa [online]. Campina Grande: EDUEPB, 2013, pp. 233-250. ISBN 9788578792824. Available from SciELO Books $<\underline{\text { http://books.scielo.org }>\text {. }}$

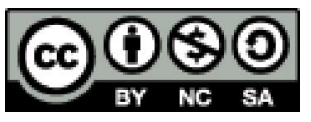

All the contents of this work, except where otherwise noted, is licensed under a Creative Commons Attribution-Non Commercial-ShareAlike 3.0 Unported.

Todo o conteúdo deste trabalho, exceto quando houver ressalva, é publicado sob a licença Creative Commons Atribuição Uso Não Comercial - Partilha nos Mesmos Termos 3.0 Não adaptada.

Todo el contenido de esta obra, excepto donde se indique lo contrario, está bajo licencia de la licencia Creative Commons Reconocimento-NoComercial-CompartirIgual 3.0 Unported. 


\title{
Aplicação de técnicas de produção mais limpa no desmonte de rocha e sua contribuição para a saúde do trabalhador
}

\author{
Julio Cesar de Pontes \\ Waleska Silveira Lira \\ Vera Lúcia Antunes de Lima
}

\section{Introdução}

A atividade da mineração necessária para o desenvolvimento industrial do país em seus mais diversos setores produtivos ao longo dos anos sempre foi um dos sustentáculos dos poderes econômico e político. Atualmente é responsável por uma parcela considerável na formação do produto interno bruto brasileiro, mesmo com esta importância, demanda uma série de procedimentos extrativos que causam severo impacto ambiental, de modo que a atual política de gestão dos recursos naturais vinculada ao conceito de sustentabilidade, a qual tem sido fomentada em foro nacional nos últimos anos, exige não apenas um planejamento estratégico consistente acerca da delimitação do espaço a ser explorado, mas também, a implantação de um modelo de gestão integrada e participativa no uso dos recursos minerais, de modo a promover o equilíbrio necessário para a manutenção do ecossistema afetado por esta atividade degradatória.

A mineração é uma atividade que trabalha no longo prazo, em um horizonte de até quarenta anos, e no decorrer desse processo dinâmico, são geradas situações e condições em que estão presentes as cargas, 
agentes, forças, entre outros elementos patógenos, os quais constituem riscos e ao mesmo tempo perigo para a saúde dos seus trabalhadores (ROUQUAYROL; ALMEIDA FILHO, 2003).

Os riscos à saúde humana, presentes na atividade de mineração, colocam os trabalhadores em contatos com agentes nocivos como: poeira gerada pela extração e processamento da brita, que além de causar desconforto ambiental, provoca diversas doenças no sistema respiratório, das quais as mais graves são as silicoses e pneumoconioses. As pessoas mais afetadas são aquelas que trabalham diretamente junto aos focos emissores de poeira (constituindo uma questão de saúde ocupacional), mas em graus variáveis compromete, também, os moradores das áreas circunvizinhas às minerações (RODRIGUES, 1993; RIBEIRO, 1995). Por sua vez, os ruídos produzidos causam danos, muitas vezes, definitivos a audição dos trabalhadores e até mesmo a população circunvizinha.

Os resíduos poluentes associados à poeira que ficam impregnados na pele das pessoas que trabalham na pedreira causam alterações e várias patologias de ordem dermatológicas; afora os danos causados nas articulações por impactos repetitivos no uso contínuo e errôneo dos equipamentos.

O uso consciente dos recursos minerais é uma das maiores preocupações relacionadas às atividades mineradoras, considerando sua importância para o desenvolvimento econômico da região, não obstante o impacto ambiental causado pelas atividades inerentes ao extrativismo.

O desmonte de rocha, com a finalidade de produzir brita a ser utilizada diretamente na construção civil, vem se dando por meio de desconforto humano e ambiental, prejudicando a saúde de trabalhadores, que estão expostos a essa atividade, bem como a saúde da população do entorno onde vem sendo desenvolvida e, também, danos às estruturas construídas e, por conseguinte, ao meio ambiente. Essa exposição pode ser configurada por meio de efeitos maléficos como os seguintes: ultralaçamento, ruído, poeira, vibração, modificações das propriedades físicas, químicas e biológicas do meio. Nesse sentido, o controle e a minimização desses efeitos é uma prática importante que deve acompanhar o planejamento e a execução dos trabalhos de desmonte de rocha (SÁNCHEZ, 1995).

Estudos sobre os procedimentos adotados no desmonte de rocha, em conjunto com o crescimento do impacto ambiental e a necessidade do conhecimento humano, evidenciam que os problemas ambientais gerados pelo desmonte são incompatíveis com o processo de regeneração do 
meio ambiente, apesar de ser essencial para o ciclo da exploração mineral. O desenvolvimento dessa atividade econômica deve ser balizado em uma visão holística pautada em planejamento estratégico que envolva os aspectos sociais, econômicos, ambientais, culturais, dentre outros, que sejam perfeitamente contemplados na exploração de rocha, conduzindo a sustentabilidade de uma dada sociedade.

É notório que vários problemas ambientais atualmente são decorrentes da utilização de técnicas com reduzida eficácia ambiental, corroborando de forma significativa na inviabilização da formação de comunidades sustentáveis.

Portanto, incorporar a preocupação ambiental, o bem-estar social com a saúde do trabalhador a partir do momento que se pretende reduzir custos e acrescentar índices de produtividade, com uma melhor imagem perante a sociedade, requer a agregação da aplicação de técnicas de Produção mais Limpa.

Segundo o Programa das Nações Unidas para o Desenvolvimento Industrial (PNUDI), Produção + Limpa requer mudanças de atitudes, gestão ambiental responsável e promoção da inovação tecnológica. $\mathrm{O}$ conceito é aplicação contínua de uma estratégia ambiental preventiva integrada aos processos, produtos e serviços para aumentar a ecoeficiência e evitar ou reduzir os danos ao homem e ao ambiente.

A partir dessa contextualização, surgiu o seguinte questionamento de investigação científica: Como a aplicação do modelo de gestão ambiental à Produção mais Limpa na atividade do desmonte de rocha contribuirá para melhorar a saúde dos trabalhadores? Em função do problema de pesquisa aqui apresentado, o objetivo deste estudo é analisar como a aplicação da Produção mais Limpa na atividade do desmonte de rocha pode contribuir para melhorar a saúde do trabalhador. Este estudo tomará como base os autores (DALLORA NETO, 2004; PONTES, 1998; ESTON, 1998; ROLIM, 1993; SÁNCHEZ, 2001 e SILVA et al 2000), no que se refere ao desmonte de rocha. Quanto à Produção mais Limpa, serão utilizados os estudos de (BARBIERI, 2004; PIMENTA, 2008; FERNANDES, 2001; HUSBAND et al., 1999; HENRIQUES; QUELHAS, 2007; UNIDO/UNEP,1995) e com relação a saúde do trabalhador serão utilizados os estudos de (GUERREIRO,1998; ROUQUAYROL; ALMEIDA FILHO, 2003; TAMBELLINI; CÂMARA, 1998; BRASIL, 2007). Assim sendo, com a realização desse estudo, espera-se obter como resultado 
os indicadores que levarão a uma Produção mais Limpa aplicada no desmonte de rocha, os quais contribuirão para uma melhor gestão integrada e participativa nesta atividade.

\section{Fundamentação teórica}

\section{Desmonte de rocha}

Cada vez mais as pedreiras estão se localizando próximas às áreas urbanas, o que implica em situações que normalmente geram conflitos junto à população. Com isso, torna-se necessário dar ênfase ao estudo do desmonte escultural, com a finalidade de diminuir os impactos causados pela mineração ou pedreira à sociedade, e ao mesmo tempo minimizar os danos causados ao meio ambiente e ao maciço remanescente.

A exploração de maciços rochosos com uso de explosivos provoca inevitáveis impactos ambientais e desconforto para as populações do entorno, as quais estão expostas cotidianamente aos seus efeitos. Dallora Neto (2004) destaca que os principais efeitos ambientais se fazem sentir através do ultralaçamento de fragmentos, da geração de vibrações no terreno, de sobrepressão atmosférica, da emissão de materiais particulados (poeira) na atmosfera, do aumento dos níveis de ruído, do assoreamento de áreas e/ou de drenagens adjacentes às minerações, além da alteração visual e paisagística. Esses problemas podem ser reduzidos a um nível aceitável pela comunidade, se a lavra for executada de modo a preservar as condições de saúde, segurança e bem-estar da população afetada, adotando-se técnicas modernas de extração e beneficiamento, e pelo monitoramento continuado dos parâmetros ambientais envolvidos, mantendo-os, no mínimo, dentro dos limites estabelecidos pelos organismos governamentais fiscalizadores.

O desmonte de rocha será eficiente se a energia do explosivo for utilizada nos seus principais objetivos que são: a fragmentação desejada, preservação do talude remanescente, formação da pilha do material adequada com os equipamentos de carregamento e transporte, e preservação da praça de lavra. E são condicionados a vários parâmetros básicos, que influenciarão diretamente sobre os custos das diversas operações unitárias, como: finalidade do material a ser trabalhado, características das rochas, situação topo-geográfica e mão-de-obra disponível. Após uma criteriosa análise desses parâmetros, é que, poderão ser definidos os investimentos de forma a viabilizar a operação do desmonte de rocha. (PONTES, 1998) 
Para a identificação dos aspectos e avaliação dos impactos ambientais associados a determinado empreendimento, deve-se procurar, inicialmente, selecionar todas as atividades, produtos e serviços relacionados à cadeia produtiva, de modo a separar o maior número possível de impactos ambientais gerados, reais e potenciais, benéficos e adversos, decorrentes de cada aspecto identificado, considerando, sempre, se são significativos ou não (SÁNCHEZ, 2001).

Os principais impactos ambientais decorrentes dos desmontes de rochas com explosivos estão associados à dissipação da fração de energia liberada pelo explosivo na detonação que não é transformada em trabalho útil. Tal fração de energia dissipa-se, em sua maior parte, através do maciço circundante sob a forma de vibrações, e da atmosfera sob a forma de ruído e sobrepressão atmosférica, que é causada pela movimentação do material desmontado ou por perda de energia durante a detonação de cargas explosivas (liberando gases confinados de modo inadequado). Esse fenômeno é normalmente mais intenso na frente da face da bancada e geralmente se confunde com o ruído da explosão. Gera, complementarmente, poeira podendo ainda ocasionar danos ao maciço remanescente e ultralaçamento (ESTON, 1998).

Desses problemas ambientais do desmonte com uso de explosivos, o ultralançamento é que representa maior perigo direto, face à possibilidade de ocasionar acidentes com vítimas fatais e danos em estruturas residenciais. Sua prevenção dá-se através da elaboração de um bom plano de fogo, não sendo, entretanto, suficiente para evitá-los. As causas de ultralançamentos citadas por Silva et al. (2000) são as seguintes: afastamento insuficiente ou excessivo; alinhamento errado dos furos; iniciação instantânea dos furos em filas consecutivas; ocorrência de anomalias geológicas; tampão inadequado e fragilidade da face livre ou ultraquebras decorrentes de detonações anteriores.

Sánchez (1995a) e Eston (1998) consideram, entretanto, que as principais fontes de sobrepressão - uma vez que definem ruído como uma sobrepressão em faixa de frequência audível - em um desmonte de rochas com explosivos estão relacionadas à liberação de gases através de fraturas e da parte superior da coluna de explosivos, com ejeção do tampão; a detonação de explosivos não confinados e a refração das ondas sísmicas através da atmosfera.

A geração de vibrações no solo é outro importante efeito da utilização de explosivos para o desmonte de rochas e causam um marcante desconforto ambiental à população. A propagação de vibrações através do terreno pode provocar trincas em construções, mas geralmente seu 
efeito se reduz ao incômodo causado às pessoas pela sensação de vibração ou tremor das edificações, marcadas algumas vezes pela oscilação e/ ou queda de objetos (CETESB, 1983).

Desde a década de 30, estudos vêm sendo realizados na busca por um estabelecimento acerca dos critérios relativos a danos e ao desconforto causado às pessoas, em decorrência de vibrações provenientes de desmontes de rochas por explosivos. Ainda segundo Rolim (1993), desde aquela época, trabalha-se em busca de uma relação empírica entre alguma medida de energia da vibração e a possibilidade de danos a residências e outras estruturas existentes na cercania; de uma relação empírica entre a carga detonada e a energia de vibração, em função da distância; limites máximos admissíveis de vibração e de medidas economicamente viáveis a serem tomadas para evitar que as vibrações ultrapassem esses limites máximos, além de aparatos capazes de captar as vibrações de maneira precisa, confiável e reprodutível.

Com a finalidade de atenuar os impactos causados ao meio ambiente, pela atividade de desmonte de rocha, um dos melhores resultados vem sendo obtidos em ações setorizadas, através da aplicação pelas empresas mineradoras de medidas efetivas de atenuação do impacto ambiental (programas de autocontrole ambiental), acompanhadas da execução de uma política de negociações com as populações vizinhas ao empreendimento mineiro (AREIA; BRITA, 1997a, 1997b; BARROS, 1997; RIBEIRO, 2003; DALLORA NETO, 2004).

\section{Riscos à saúde dos trabalhadores}

O ser humano utiliza os recursos naturais desde a sua existência, uma vez que depende deles para várias atividades e sobrevivência. Entretanto, para utilizá-los termina por contaminar ou destruir, quando não planejado, o meio-ambiente ao mesmo tempo em que adoece, ou seja, prejudica a sua saúde.

Dentro da versão saúde pública, está inserido um capítulo intitulado "saúde do trabalbador". É indiscutível a grande evolução deste capítulo nos últimos vinte e cinco anos. Isto, porque o constante avanço, a globalização, a complexidade dos efeitos e dos processos produtivos sobre a vida biológica e social do planeta tem tornado cada dia evidente a necessidade do aumento nos cuidados da saúde dos trabalhadores.

Analisando de forma sistemática a questão saúde do trabalhador, observa-se que existe uma inter-relação entre vários aspectos econômicos, tecnológicos, sociais, biológicos, produtivos e físicos. Segundo os 
estudos de Tambellini (1974), os mesmos apontam para a gravidade dos problemas da saúde dos trabalhadores brasileiros, em decorrência dos processos de trabalhos a que estes estão submetidos. Esses processos discorrem para a efetiva avaliação dos riscos proporcionados à sua saúde.

Os riscos presentes nos ambientes de trabalho, responsáveis por acidentes e geração de doenças, impulsionaram, a partir da década de 70, o campo de estudo da saúde do trabalhador (TAMBELLINI; CÂMARA, 1998). Isto só se tornou evidente a partir do surgimento do mercantilismo e posteriormente do capitalismo, onde, como consequência, veio uma carga excessiva de trabalho e maior exposição aos fatores de risco à saúde do trabalhador.

A Constituição Brasileira em seu artigo 196 diz: a Saúde é direito de todos e dever do Estado, garantindo mediante políticas sociais e econômicas que visem à redução do risco de doença e de outros agravos e ao acesso universal e igualitário às ações e aos serviços para sua promoção, proteção e recuperação (BRASIL, 2007).

Já as Leis Orgânicas da Saúde (LOS), que são a Lei 8.080/90 e a Lei 8.142/90, servem para dar cumprimento ao mandamento constitucional e disciplinar à proteção e defesa da saúde. Já a Lei no 8.213/91, Lei de Planos e Benefícios da Previdência Social, cumprindo a previsão constitucional, prevê a proteção dos trabalhadores com a cobertura dos riscos sociais da incapacidade laborativa por meio de três benefícios previdenciários, aplicáveis a determinadas situações concretas e relativas à duração maior ou menor da incapacidade, como sejam: auxílio-doença acidentário (arts. 59 e 61), auxílio-acidente (art. 86) e aposentadoria por invalidez acidentária (art. 44).

Em 1999, foi criada, nos Estados Unidos da América, a Norma OHSAS 18001 (Occupational Health and Safety Assessment Serie), a qual foi atualizada em 2007 e tem como objetivo ajudar as organizações a formularem melhores práticas com a principal função de proteger e assegurar aos trabalhadores, um ambiente de trabalho saudável e seguro. Um dos requisitos da norma é o estabelecimento de procedimento(s) para identificação de perigos, avaliação de riscos e determinação de medidas de controle. Isto demonstra que a empresa está disposta a preservar a saúde e segurança dos seus trabalhadores, fazendo com que exista ganho de produtividade e redução de incidentes e acidentes de trabalho. Esta norma possui compatibilidade com as normas das séries ISO 9000 e ISO 14000 para certificação de qualidade. (Norma OHSAS 18001) 
Diante disto, cabe ressaltar que a saúde do trabalhador e os acidentes de trabalho constituem uma área de Saúde Pública que tem como objeto de estudo e intervenção as relações entre o trabalho e saúde; logo as ações voltadas para esta problemática apresentam dimensões sociais, políticas e técnicas.

É no decorrer do processo de produção, que os trabalhadores ficam expostos às várias categorias de situações de riscos tais como: químicos, biológicos, físicos, mecânicos, ergonômicos e psicossociais (ROUQUAYROL; ALMEIDA FILHO, 2003). Transferindo isto para o setor mineral, as alterações ambientais independentes das tecnologias ou até mesmo do uso rudimentar que em muitos locais são empregados, não buscaram, ao longo do tempo, atingir medidas necessárias e suficientes que objetivassem a defesa da saúde dos seus trabalhadores. Nesse contexto, as doenças ocupacionais se enquadram como resultado dos determinantes lesivos ao organismo do trabalhador, tais como: poeira, sílica, tempo de exposição aos ruídos, ao sol, contato com substâncias tóxicas e explosivas, bem como os esforços repetitivos e até mesmo a forma de locomoção entre seu setor de trabalho, sua residência ou seu alojamento.

Deste modo, o campo da saúde do trabalhador abrange, também, a saúde ambiental, a qual compreende a área de saúde pública relacionada com o conhecimento científico e as formulações de políticas e as correspondentes intervenções relacionadas à interação entre saúde humana e os fatores do meio ambiente natural e antrópico que a determinam, condicionam e influenciam, com vistas a melhorar a qualidade de vida do ser humano sob o ponto de vista da sustentabilidade (BRASIL, 2007).

Neste estudo, onde a interdisciplinaridade da exploração dos recursos naturais aflora a exposição dos trabalhadores aos fatores de riscos, serão levantados dados concernentes às políticas públicas de saúde, às condições dos trabalhadores analisados e aos seus parâmetros de avaliação, visando a orientá-los, assim como o empregador.

\section{Produção mais Limpa}

A Produção mais limpa $(\mathrm{PmL})$ tem suas origens nas propostas correlatas estimuladas pela Conferência de Estocolmo de 1972, como o conceito de tecnologia limpa (clean technology), um conceito de tecnologia que deveria alcançar três propósitos distintos, porém complementares: lançar menos poluição ao meio ambiente, gerar menos resíduos e 
consumir menos recursos naturais, principalmente os não-renováveis . (BARBIERI, 2004).

De acordo com UNIDO (2006), a PmL consiste em uma estratégia preventiva e integrativa, que é aplicada a todo ciclo de produção para fazer: a) aumentar a produtividade, assegurando um uso mais eficiente da matéria-prima, energia e água; b) promover melhor performance ambiental, através da redução de fontes de desperdícios e emissão; c) reduzir impacto ambiental por todo ciclo de vida de produto através de um desenho ambiental com baixo custo efetivo.

Segundo SEBRAE (2011), Produção mais Limpa é a aplicação de uma estratégia técnica, econômica e ambiental integrada aos processos e produtos, a fim de aumentar a eficiência no uso de matérias-primas, água e energia, através da não geração, minimização ou reciclagem dos resíduos e emissões geradas, com benefícios ambientais de saúde ocupacional.

Já de acordo com CEBDS (2004), entende-se como Produção mais Limpa, a aplicação contínua de uma estratégia ambiental preventiva e integrada a processos, produtos e serviços para aumentar a eficiência global e reduzir riscos aos seres humanos e ao ambiente natural.

De forma geral, vale destacar alguns elementos-chave formadores do conceito de PmL, sendo eles: estratégia, prevenção, integração e redução de risco. Desta forma, pode-se considerar a PmL como uma Ferramenta de Gestão Ambiental aplicada a partir de uma estratégia preventiva e integrativa, tanto para serviços quanto para processos e produtos, de forma a se reduzir os riscos ambientais e ao homem (Figura 1).

Figura 1 - Representação esquemática do conceito de $\mathrm{PmL}$ proposto.

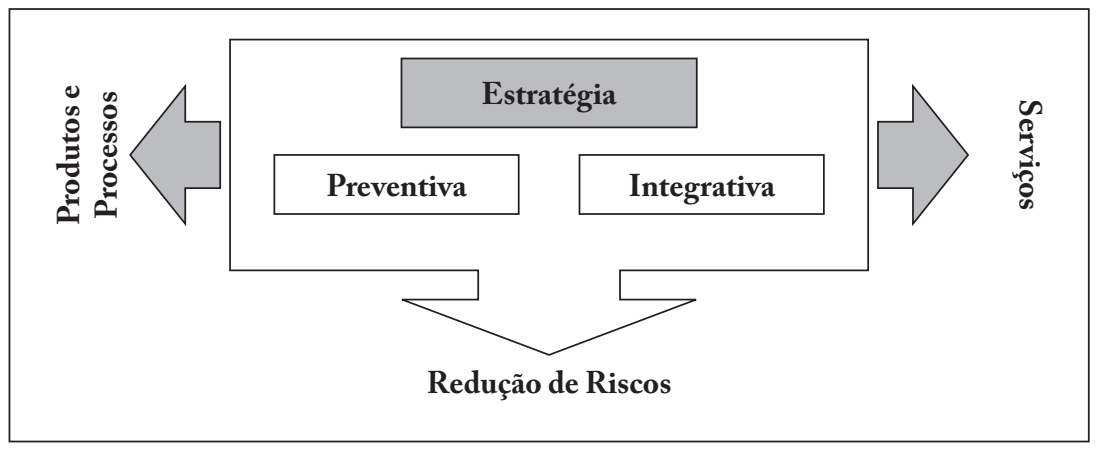

Fonte: Pimenta (2008) 
A preocupação de ter um marco teórico da Produção mais Limpa, parte de um entendimento errôneo em pensar que a PmL trata-se de uma fase posterior à implementação de um sistema de gestão ambiental. Vale salientar que essa ferramenta tem se mostrado como uma forma efetiva de controle da poluição e de redução de impactos ambientais (PIMENTA, 2008).

Segundo Husband et al. (1999), custos, tempo e outros impactos não explicam totalmente porque as pequenas e médias empresas não têm adotado os métodos de qualidade num nível significativo. A falta de entendimento e a baixa interpretação desses métodos por parte dos proprietários, gerentes e operadores das pequenas e médias empresas podem justificar o pouco uso desses métodos. A Produção mais Limpa pode ser facilmente comparada a um desses métodos de qualidade e dessa forma, encontra na falta de conhecimento das empresas, a respeito dos benefícios trazidos pelo uso dessa metodologia, uma barreira para sua implementação.

Baseado no conceito proposto por Fernandes (2001), a Produção mais Limpa pressupõe quatro atitudes básicas. A primeira, e a mais importante, é a busca pela não geração de resíduos, através da racionalização das técnicas de produção; a segunda atitude proposta é a minimização da geração dos resíduos; a terceira atitude é o reaproveitamento dos resíduos no próprio processo de produção, enquanto a quarta alternativa é a reciclagem, com o aproveitamento das sobras ou do próprio produto para a geração de novos materiais (CETESB, 2007 apud HENRIQUES; QUELHAS, 2007).

Adaptando este conceito para o desmonte de rocha, impõe-se a questão ambiental através da redução na eliminação ou minimização dos riscos ao trabalhador, tornando-se possível a adequação aos requisitos do desenvolvimento sustentável, dentro de uma condição essencialmente relacionada à "ecoeficiência". Logo, qualquer que seja o modelo utilizado terá que provê métodos de análise dos impactos socioambientais e propor soluções econômicas e técnicas que visem à melhoria na produção da empresa e principalmente prevenir e melhorar a saúde dos trabalhadores.

A Ferramenta de Gestão Ambiental Produção mais Limpa, aplicada a partir de uma estratégia preventiva na atividade do desmonte de rocha, verificando-se as etapas de decapeamento do terreno, desmonte, carregamento e transporte, visa a minimizar os impactos ambientais 
e o risco aos trabalhadores através da identificação dos elementos das atividades que interagem com o meio ambiente, ou seja, os aspectos ambientais. Assim, pode-se observar que o foco dado na gestão através da PmL é preventivo, já que a causa dos impactos e riscos é priorizada. $\mathrm{Na}$ figura 2, a seguir, serão apresentados os aspectos ambientais significativos das atividades deste estudo.

Figura 2 - Fluxograma da atividade de desmonte de rocha.

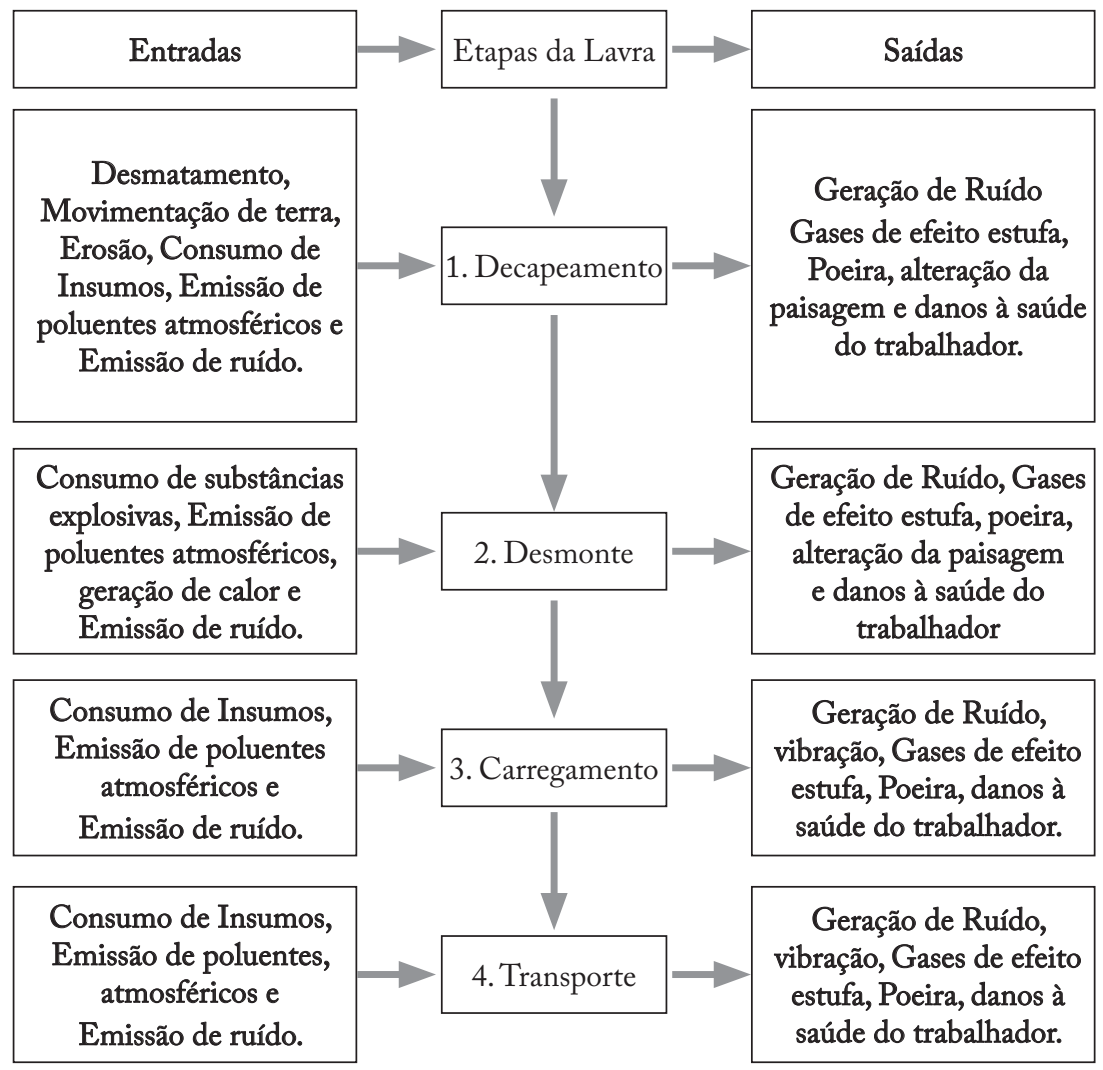

Fonte: Autoria própria, 2011.

Com base na figura 2, é possível enumerar cada etapa da atividade do desmonte de rocha como: decapeamento do terreno, desmonte, carregamento e transporte. Pode-se, também, identificar os aspectos ambientais de cada fase, a saber: de entrada - desmatamento, movimentação de terra, erosão, consumo de insumos, emissão de poluentes atmosféricos, emissão de ruído, consumo de substâncias explosivas, 
geração de calor; e de saída - geração de ruído, vibração, gases de efeito estufa, poeira, alteração da paisagem e danos à saúde do trabalhador.

Uma vez identificados estes aspectos ambientais, é fundamental, segundo a metodologia de Produção mais Limpa, diagnosticar as possíveis causas de sua geração, assim como os impactos gerados pela atividade como todo.

Portanto, para identificação e análises dos aspectos ambientais relacionados com o desmonte de rocha e a pressão na saúde do trabalhador, o quadro 01, a seguir, relaciona os diversos aspectos ambientais de entradas e saídas nas diversas etapas desta atividade e os riscos a que estão expostos os trabalhadores.

\section{Quadro 1 - Análise da pressão da saúde do trabalhador} a partir dos aspectos ambientais.

\begin{tabular}{|c|c|c|c|c|c|}
\hline \multirow{2}{*}{ Aspectos Ambientais } & \multicolumn{5}{|c|}{ Pressão na Saúde do Trabalhador } \\
\hline & Físico & Químico & Biológico & Mecânico & Ergonômico \\
\hline Desmatamento & $\mathrm{X}$ & & & & \\
\hline Erosão & $\mathrm{X}$ & & & $\mathrm{X}$ & \\
\hline Consumo de insumos & & $\mathrm{X}$ & & & $\mathrm{X}$ \\
\hline Consumo de substâncias explosivas & $\mathrm{X}$ & $\mathrm{X}$ & & $\mathrm{X}$ & $\mathrm{X}$ \\
\hline Geração de ruído & $\mathrm{X}$ & & & & \\
\hline \multicolumn{6}{|l|}{ Geração de calor } \\
\hline \multicolumn{6}{|l|}{ Emissão de poluentes } \\
\hline Geração de gases de efeito estufa & $\mathrm{X}$ & & & & \\
\hline Geração de poeira & & $\mathrm{X}$ & & & \\
\hline Geração de resíduos sólidos & $\mathrm{X}$ & & & $\mathrm{x}$ & \\
\hline Ultralançamento & & & & $\mathrm{x}$ & \\
\hline Vibração & $\mathrm{x}$ & & & & \\
\hline
\end{tabular}

Fonte: Autoria

Deste modo, a partir de uma análise realizada em consonância com os aspectos ambientais e as pressões na saúde do trabalhador, podemse constatar diversos riscos para a saúde, dentre eles: físicos, químicos, biológicos, mecânicos e ergonômicos. Santos (2008) cita que os riscos físicos são efeitos gerados por máquinas, equipamentos e condições 
físicas características do local de trabalho, que podem causar danos à saúde do trabalhador. Os riscos químicos são representados pelas substâncias químicas que se encontram nas formas líquida, sólida e gasosa. Os riscos biológicos são causados por microrganismos invisíveis a olho nu, como bactérias, fungos, vírus e bacilos. Os riscos mecânicos ocorrem em função das condições físicas do ambiente do trabalho e tecnologias impróprias, capazes de colocar em perigo a integridade física do trabalhador. E finalmente, os riscos ergonômicos são contrários às técnicas de ergonomia, que propõem que os ambientes de trabalho devem-se adaptar ao homem, propiciando bem-estar físico e psicológico.

\section{Considerações Finais}

A atividade da mineração provoca impactos em todas as fases do empreendimento tais como: pesquisa, implantação, operação e desativação da lavra. Durante a fase de operação do desmonte de rocha e deposição do estéril, tanto a mineração a céu aberto quanto a subterrânea modificam e degradam o meio ambiente, uma vez que promovem a alteração das propriedades físicas, químicas e biológicas do meio onde está inserida. Seu reflexo pode expandir-se além da área diretamente afetada, apresentando um grau de impacto ambiental de alta magnitude, como nos casos onde há contaminação por metais pesados ou a ocorrência de drenagem ácida, atingindo os corpos d'água, causando danos à fauna e à flora e aos trabalhadores envolvidos.

Assim sendo, é nítida a importância de se aplicar um modelo de gestão ambiental na atividade do desmonte de rocha, com o objetivo de melhorar as condições do meio, a saúde e segurança do trabalhador, permitindo dessa forma obter indicadores de eficiência. No entanto, não se tem conhecimento, na literatura pesquisada, de estudos que incluam a aplicação de um modelo de ferramentas de gestão ambiental, como Produção mais Limpa na atividade do desmonte de rocha utilizando substâncias explosivas.

Existem linhas de pesquisa que estudam a Produção mais Limpa em casos específicos de projetos de desenvolvimento de produto, enfocando a influência do conhecimento na busca de soluções. Portanto, não foi encontrado nenhum estudo com a preocupação efetiva de propor um sistema de gerenciamento do conhecimento na aplicação da Produção mais Limpa no desmonte de rocha. Desta forma, essas lacunas teóricas a serem exploradas constituem uma das justificativas para a realização do presente estudo. 
Diante do exposto, a aplicação da Produção mais Limpa é de fundamental importância para minimizar os impactos ambientais e sensibilizar a sociedade para melhor aproveitar os recursos naturais existentes, pois visa a reduzir custos operacionais, além de buscar soluções economicamente viáveis para a redução da geração dos resíduos, ou até mesmo a não-geração de "sobras" nas etapas ao longo do processo produtivo, conforme destacam Henriques e Quelhas (2007).

Portanto, a aplicação dessa ferramenta de gestão ambiental contribuirá para a geração de uma gestão integrada e participativa nesta atividade, oportunizando melhor contribuição para a saúde do trabalhador. 


\section{Referências}

COMO vive uma pedreira no meio da cidade. Areia \& Brita. Pedreira Itaquera, n.1, p. 22-26, [1997]a.

$$
\text { .n.2, p. 3-11,[1997]b. }
$$

BARBIERI. C. Gestão ambiental empresarial: conceitos, modelos e instrumentos. São Paulo, Ed. Saraiva, 2004.

BARROS, F.L.C. A mineração de agregados na região metropolitana de São Paulo In; CONGRESSO BRASILEIRO DE MINERAÇÃO (IBRAM), p. X-21-X-34, 1997.

BRASIL. Subsídios para a Construção da Política Nacional de Saúde Ambiental. [Brasília]: Ministério da Saúde; Conselho Nacional de Saúde, 2007.

CONSELHO EMPRESARIAL BRASILEIRO PARA O DESENVOLVIMENTO SUSTENTÁVEL (CEBDS). Guia da Produção Mais Limpa: Faça você Mesmo. Disponível em: <www.pmaisl.com.br>. Acesso em: jan. 2004.

COMPAHIA DE TECNOLOGIA DE SANEAMENTO AMBIENTAL (CETESB). Reestudo dos críticos de análise do incômodo causado aos indivíduos por vibrações. São Paulo: CETESB, 1983. 51 p.

DALLORA NETO, C. Análise das vibrações resultantes do desmonte de rocha em mineração de calcário e agilito posicionada junto á área urbana de Limeira (SP) e sua aplicação para minimização de impactos ambientais. Rio Claro,., 82 p. Dissertação (Mestrado em Geociências e Ciências Exatas) - Instituto de Geociência e Ciências Exatas, Universidade Estadual Paulista, 2004.

ESTON, S.M. Uma análise de nível de vibração associados a detonações. 125, p. Tese (Doutorado em Livre Docência)- Escola Politécnica, Universidade de São Paulo, São Paulo, 1998. 
FERNANDES, J. V. G et al. Introduzindo práticas de produção mais limpa em sistemas de gestão ambiental certificáveis: uma proposta prática. Revista Engenharia Sanitária e Ambiental, Rio de Janeiro, v. 6, n. 3, jul/dez., 2001.

GUERREIRO, H.; PEREIRA, S.; LEITÃO, A. Sector das Rochas Ornamentais - Manual de Prevenção. Lisboa: Ed. Por IDICT - Instituto de Desenvolvimento e Inspeção das Condições de Trabalho, 1998. (Série de Informação Técnica; 8).

HENRIQUES, L. P.; QUELHAS, O. L. G. Produção Mais Limpa: Um exemplo para sustentabilidade nas organizações. 2007. Disponível em:

<http://www1.sp.senac.br/hotsites/sigas/docs/20071016_CAS_

ProducaoMaisLimpa.pdf >. Acesso em: 23 abr. 2011.

HUSBAND, S.; MANDAL P. A conceptual model for quality integrated management in small and medium size enterprises. The International Journal of Quality \& Reliability Management, v. 16, n. 7, p. 699-713, 1999.

IMPLEMENTATION. Draft, 30 June, 1995d.

PIMENTA, Handson Cláudio Dias. A produção mais limpa como ferramenta em busca da sustentabilidade empresarial: um estudo de múltiplos casos em empresas do estado do Rio Grande do Norte, 2008. 174 f. Dissertação (Mestrado em Ciências em Engenharia de Produção) Programa de Pós-Graduação em Engenharia de Produção, Universidade Federal do Rio Grande do Norte, Natal, 2008.

PLANNING and Organization. Draft, 30 June 1995c

PONTES, J.C. Estudo da Fragmentação em Desmonte com Explosivos na Pedreira Queimadas - PEDRAQ, Queimadas-PB, 128p, 1998.

RIBEIRO, J.T.M. Curso básico sobre medição, prevenção e controle da poluição na mineração (poeira e ruído). São Paulo: DNPM/ CECOPOMIM, 28 p.,1995. 
ROLIM, F. J. L. . Considerações sobre desmontes de rochas com ênfase aos basaltos feição entablamento, p 17; 54; 57; 64; 76; 102 e 109. Escola de Engenharia de São Carlos - SP, 1993.

ROGRIGUES, G.L. Efeitos ambientais na produção de brita em área urbanas (poluição atmosférica e vibração). 1993,78p. Dissertação (Mestrado em Geociências) - Instituto de geociências, Universidade de São Paulo, 1993.

ROUQUAYROL, M Z; ALMEIDA FILHO, N. 2. ed. Epidemiologia \& Saúde. Rio de janeiro: Guanabara-Koogan, 728p, 2003.

SANTOS, Definição de Riscos Ambientais no Trabalho. 22 de Junho (2008) Disponível em:< http://pt.shvoong.com/medicine-and-health/epidemiology-public-health/1821378>. Acesso em: maio 2011.

SÁNCHEZ, L.E. Ruído y Sobrepresion atmosférica. In: REPETTO, F.L.; KAREZ, C.S (Eds), Aspectos Geológicos de proteccion ambiental. Montevideo: PNUMA/UNESCO; Instituto de Geociência/UNICAMP, v.1, p.189-196, 1995(a)

SÁNCHEZ. L. E. Sistemas de gestão ambiental. Apostila didática de aulas. Curso ministrado na Escola Politécnica, Universidade de São Paulo. Pós-Graduação, ano letivo 2001.

SEBRAE. A Produção mais Limpa na Micro e Pequena Empresa. Disponível em: <www.pmaisl.com.br>. Acesso em: abr. 2011.

SEIFFERT, M E B - Importância das Normas OHSAS 18001 e ISO 14001. In: SISTEMA DE GESTÃO AMBIENTAL (ISO 14001) e Saúde Ocupacional (OHSAS) - Vantagens da Implantação Integrada. 2. ed. São Paulo: Editora Atlas, 2010.

SILVA, V.C.; ANTONINI, A.; KOPPE, J.; FLOYD, J.; CERRELO, L.; CROSBY, W.; HOGAN, T. Problemas Gerados Pelas Detonações. Rio Claro: Instituto de Geociências e Ciências Exatas. Universidade Estadual Paulista, 165p., 2000. 
TAMBELlinE, A. T., 1974. Contribuição à Análise Epidemiológica dos Acidentes de Trânsito. Tese (Doutorado em Saúde Pública) - Campinas: Universidade de Campinas, 1974.

TAMBELLINE; CÂMARA, V.M. A temática saúde e ambiente no processo de desenvolvimento da Saúde Coletiva: aspectos históricos, conceituais e metodológicos. Ciência e Saúde Coletiva, v.3, n.2, p.47-59, 1998.

UNEP - How Can Educational Institutions Promote Cleaner Production. 2006, Disponível em: <http://www.uneptie.org/pc/cp/understanding_cp/other_cp_stakeholders.htm 2 > acesso em: 19 abr. 2011.

UNIDO/UNEP. Manual (a) Cleaner Production Assesmente Manual. Part One Introdution to Cleaner Production. Draft, 30 June 1995 a .

.(b). Cleaner Production Assesmente Manual. Part four. Draft, 30 June 1995b

.(c). Cleaner Production Assesmente Manual. Part Four. Phase I,

.d) Cleaner Production Assesmente Manual. Part Four. Phase V,

UNIDO. Manual on the development of cleaner productions policies approaches and instruments. Disponível em <www.unido.org $>$. Acesso em: outubro/2006. 